\title{
Modelling Rates of Gasification of a Char Particle in Chemical Looping
}

Combustion

Marco A. Saucedo ${ }^{\mathrm{a}^{*}}$, John S. Dennis ${ }^{\mathrm{a}}$, Stuart A. Scott ${ }^{\mathrm{b}}$

${ }^{a}$ Department of Chemical Engineering and Biotechnology, University of Cambridge, Pembroke Street, Cambridge, CB2 3RA, United Kingdom

${ }^{\mathrm{b}}$ Department of Engineering, University of Cambridge, Trumpington Street, Cambridge, CB2 1PZ, United Kingdom

\section{*Corresponding author}

Department of Chemical Engineering and Biotechnology

University of Cambridge

New Museums Site

Pembroke Street,

Cambridge, CB2 3RA,

United Kingdom

Phone: +44 1223762962

E-mail: mas225@cam.ac.uk

Colloquium that describes the research topic:

STATIONARY COMBUSTION SYSTEMS AND ENVIRONMENTAL IMPACT Alternatives:

HETEROGENEOUS COMBUSTION AND MATERIALS SYNTHESIS

REACTION KINETICS

Total length of paper: $\quad \mathbf{6 , 1 6 8}$ words (as determined by Method 1)

Equivalent length:

\begin{tabular}{lr}
\hline & Word count (M1) \\
\hline Main text & $\mathbf{3 , 4 1 1}$ \\
Equations & $\mathbf{8 0 6}$ \\
Nomenclature & $\mathbf{3 8 8}$ \\
References & $\mathbf{3 6 8}$ \\
Tables: & - \\
Table 1: & $\mathbf{6 9}$ \\
Table 2: & $\mathbf{1 2 2}$ \\
Table 3: & $\mathbf{7 6}$ \\
Figures with captions: & - \\
Figure 1: & $\mathbf{2 2 0}$ \\
Figure 2: & $\mathbf{1 6 3}$ \\
Figure 3: & $\mathbf{1 6 3}$ \\
Figure 4: & $\mathbf{1 9 1}$ \\
Figure 5: & $\mathbf{1 9 1}$ \\
\hline Total word count $=$ & $\mathbf{6 , 1 6 8}$ \\
\hline
\end{tabular}

N.B. No colour reproduction charges applicable. 


\begin{abstract}
Rates of gasification of lignite char were compared when gasification with $\mathrm{CO}_{2}$ was undertaken in a fluidised bed of either (i) an active Fe-based oxygen carrier used for chemical looping or (ii) inert sand. The kinetics of the gasification were found to be significantly faster in the presence of the oxygen carrier, especially at temperatures above $1123 \mathrm{~K}$. An analytical solution assuming pseudo-binary diffusion of species was developed to account for external and internal mass transfer and for the effect of the looping agent. The model also included the effects of the evolution of the pore structure at different conversions. The results are compared with a full numerical model using the Stefan-Maxwell equations. Excellent agreement was observed between the rates predicted by the two models and those observed experimentally at $T \leq 1123 \mathrm{~K}$. At $1173 \mathrm{~K}$, the pseudo-binary model predicted slightly higher rates than the full numerical solution. It was found that a significant share of the error of the predicted rates with the analytical solution was caused by an underestimation of intraparticle diffusional resistance rather than by assuming a pseudo-binary system external to the particle. Both models suggested that the presence of $\mathrm{Fe}_{2} \mathrm{O}_{3}$ led to an increase in the rate of gasification because of the rapid oxidation of $\mathrm{CO}$ by the oxygen carrier to $\mathrm{CO}_{2}$. This resulted in the removal of $\mathrm{CO}$ and maintained a higher mole fraction of $\mathrm{CO}_{2}$ in the mixture of gas around the particle of char, i.e. within the mass transfer boundary layer surrounding the particle. This effect was most prominent at $\sim 20 \%$ conversion when (i) the surface area for reaction was a maximum and (ii) because of the accompanying increase in porosity, intraparticle resistance to gas mass transfer within the particle of char had fallen, compared with that in the initial particle.
\end{abstract}

\title{
Keywords
}

Chemical-looping combustion; gasification; coal; $\mathrm{CO}_{2}$ separation; fluidisation 


\section{Nomenclature}

$A_{2 c k_{1}} \quad$ Pre-exponential factor for the rate constant $2 c k_{1}, \mathrm{~mol} \mathrm{~s}^{-1} \mathrm{~g}^{-1} \mathrm{bar}^{-1}$

$A_{2 c k_{1}} \quad$ Pre-exponential factor for the rate constant $2 c k_{2}, \mathrm{~mol} \mathrm{~s}^{-1} \mathrm{~g}^{-1}$

$A_{k_{-1} / k_{1}} \quad$ Pre-exponential factor for the rate constant $k_{-1} / k_{1}$, -

$c \quad$ Concentration of active sites per unit mass of carbon, $\mathrm{g}^{-1}$

$C_{T} \quad$ Total concentration in the fluidized bed, $\mathrm{mol} \mathrm{m}^{-3}$

$D_{B, a b} \quad$ Molecular diffusivity, involving species $a$ in $b, \mathrm{~m}^{2} \mathrm{~s}^{-1}$

$D_{e q} \quad$ Effective diffusivity in a fluidised bed $=D_{m} \varepsilon_{m}, \mathrm{~m}^{2} \mathrm{~s}^{-1}$

$D_{m} \quad$ Constant mean diffusivity, $\mathrm{m}^{2} \mathrm{~s}^{-1}$

$E_{j} \quad$ Activation energy for the rate constant $j, \mathrm{~kJ} \mathrm{~mol}^{-1}$

$f(X) \quad$ Relative change in the surface area available for reaction over conversion, -

$J_{\mathrm{a}} \quad$ Total flux of species $a, \mathrm{~mol} \mathrm{~m}^{-2} \mathrm{~s}^{-1}$

$k \quad$ Reaction rate constant, $\mathrm{mol} \mathrm{s}^{-1} \mathrm{~m}^{-3} \mathrm{bar}^{-1}$

$k_{l} \quad$ Rate constant for the reaction of $\mathrm{CO}$ with iron oxide $\left(\mathrm{Fe}_{2} \mathrm{O}_{3}\right), \mathrm{s}^{-1}$

$k_{1}, k_{-1} \quad$ Rate constants of gasification per active site, $\mathrm{mol} \mathrm{s}^{-1} \mathrm{bar}^{-1}$

$k_{2} \quad$ Rate constant of gasification per active site, $\mathrm{mol} \mathrm{s}^{-1}$

$K_{i} \quad$ Adsorption equilibrium constant of $i$-th species, bar $^{-1}$

$K_{p} \quad$ Equilibrium constant for the overall gasification reaction $\mathrm{C}+\mathrm{CO}_{2}=2 \mathrm{CO}$, -

$L \quad$ Thickness of catalyst (=char), $\mathrm{m}$

$p_{i} \quad$ Partial pressure of gaseous species $i$, bar

$p_{i, b u l k} \quad$ Partial pressure of gaseous species $i$ at the bulk or particulate phase, bar

$p_{i, s} \quad$ Partial pressure of gaseous species $i$ at the surface of the particle, bar

$r_{g} \quad$ Reaction rate of carbon per gross volume, $\mathrm{mol} \mathrm{s}^{-1} \mathrm{~m}^{-3}$

$R_{p} \quad$ Initial radius of a char particle, $\mathrm{m}$

$R \quad$ Universal gas constant, $\mathrm{kJ} \mathrm{mol}^{-1} \mathrm{~K}^{-1}$

$R_{g}^{\prime} \quad$ Rate of gasification of char per unit mas of sample, $\mathrm{mol} \mathrm{s}^{-1} \mathrm{~g}^{-1}$

$R_{g, 0}^{\prime} \quad$ Intrinsic rate of gasification of char at zero conversion, $\mathrm{mol} \mathrm{s}^{-1} \mathrm{~g}^{-1}$

$T \quad$ Temperature, $\mathrm{K}$

$X \quad$ Conversion of carbon, -

$y_{i} \quad$ Mole fraction of species $i,-$

$y_{i, b u l k} \quad$ Mole fraction of species $i$ in the fluidising gas (or bulk phase), -

$y_{i, s} \quad$ Mole fraction of species $i$ at the surface of the particle, -

\section{Greek letters}

$\alpha \quad$ Parameter defined in Eq. (19), -

$\delta \quad$ Thickness of the mass transfer boundary layer, $\mathrm{m}$

$\varepsilon_{o} \quad$ Initial porosity of the char, - 
$\varepsilon_{m f} \quad$ Void fraction in a bed, -

$\lambda \quad$ Correction factor in Eq. (19), -

$\phi^{*} \quad$ Reduced Thiele modulus $=\phi_{M} / \phi_{c},-$

$\phi_{c} \quad$ Critical Thiele modulus, -

$\phi_{M} \quad$ Modified Thiele modulus defined in Eq. (17) -

$\eta_{\text {in }} \quad$ Effectiveness factor of the extent of mass transfer limitations within the particle, -

$\rho_{e} \quad$ Density of a particle of char before reaction, $\mathrm{kg} \mathrm{m}^{-3}$

$\sigma_{r} \quad$ Dimensionless radius, defined as $r / R_{p}$, -

$\tau_{e x t}^{2} \quad$ Tortuosity factor of the region around the particle of pellet, -

$\tau_{i n}^{2} \quad$ Tortuosity factor of the particle, -

$v_{\mathrm{a}} \quad$ Stoichiometric coefficient of species $a$

$\omega \quad$ Parameter defined in Eq. (16), - 


\section{Introduction}

In the chemical looping combustion of coal and char, solid fuel must be gasified in pure $\mathrm{CO}_{2}$ or steam, or mixtures thereof, in situ with particles of a solid oxygen carrier, typically a transition metal oxide, which oxidises the resulting synthesis gases and volatile matter. Generally, gasification is much slower than the reactions between synthesis gases and the metal oxide [1-4]. A consequence of a slow rate of gasification is that the inventory of char in the system becomes substantial, making separation of the particles of fuel and oxygen-carrier problematic [1-9] prior to re-oxidising the carrier with air and so causing $\mathrm{CO}_{2}$ to contaminate the resulting depleted stream of air.

In a chemical-looping reactor, gasification will occur with a high $\left[\mathrm{CO}_{2}\right]$ and, or, $\left[\mathrm{H}_{2} \mathrm{O}\right]$, whilst $\mathrm{CO}$ and $\mathrm{H}_{2}$, which inhibit gasification, are consumed by reaction with the oxygen carrier [10-12]. Thus, rates of gasification should be faster in a chemical-looping system than in a normal gasifier. Here, we investigate, experimentally and theoretically, the effect of iron oxide on the rate of gasification of lignite char by $\mathrm{CO}_{2}$ :

$$
\mathrm{C}_{(\mathrm{s})}+\mathrm{CO}_{2(\mathrm{~g})} \rightarrow 2 \mathrm{CO}_{(\mathrm{g})} \Delta H_{1173 K}^{0}=+173 \mathrm{~kJ} \mathrm{~mol}^{-1}
$$

This is accompanied by Reaction (2), in Table 1, giving a net enthalpy of $+95.8 \mathrm{~kJ} \mathrm{~mol}^{-1}$ for complete conversion of the char. Reaction (2) occurs at $1173 \mathrm{~K}$ provided $p_{\mathrm{CO}} / p_{\mathrm{CO}_{2}}>1.5 \times 10^{-5}$ [13] whilst for Reaction (3), $p_{\mathrm{CO}} / p_{\mathrm{CO}_{2}}>0.6$. Accordingly, only Reaction (2) is relevant in combusting systems [5].

\section{[Table 1 hereabouts]}

\section{Experimental}

Fuel and preparation of the char. Char made from Hambach lignite coal (RWE Power AG, Germany) was investigated, with ultimate and proximate analyses given in Table 2 . The char was prepared by pyrolysing the lignite in nitrogen in an electrically-heated, stainless-steel fluidised bed (i.d. $78 \mathrm{~mm}$ ) of sand at $1073 \mathrm{~K}$. Further details of the apparatus and method are given elsewhere ([4-5],[14]). The char was sieved to +600, $1000 \mu \mathrm{m}$.

[Table 2 hereabouts] 
Oxygen carrier. Iron oxide particles were prepared by spraying $\mathrm{Fe}_{2} \mathrm{O}_{3}$ powder (Sigma-Aldrich, $<5 \mu$ m, $>99$ wt.\% purity) with reverse-osmosis water and mixing manually to form agglomerates. These were gently sieved to $+300,-425 \mu \mathrm{m}$, placed in crucibles and calcined in a muffle oven at $1223 \mathrm{~K}$ for 3 hours. Once cooled, the particles were re-sieved to $+300,-425 \mu \mathrm{m}$. The particle density, measured by helium pycnometry, was $\sim 5380 \mathrm{~kg} \mathrm{~m}^{-3}$. The fresh particles of iron oxide had a BET area of $\sim 1 \mathrm{~m}^{2} \mathrm{~g}^{-1}$. Experiments were also undertaken in the absence of oxygen carrier by replacing it with inert, uncrushed silica sand (fraction C, David Ball Group plc.), sieved to $+300,-425 \mu \mathrm{m}$. The particle density of the sand was $\sim 2690 \mathrm{~kg} \mathrm{~m}^{-3}$.

Apparatus and method. Batch experiments were performed at ambient pressure in a fluidised bed contained in a quartz reactor, i.d. $30 \mathrm{~mm}$, length $460 \mathrm{~mm}$, with a porous distributor $(4 \mathrm{~mm}$ thick frit, pore size $+100,-160 \mu \mathrm{m})$, giving a pressure drop sufficient to ensure uniform fluidisation, situated $110 \mathrm{~mm}$ from the base of the reactor. Details of the apparatus can be found elsewhere [14]. The reactor was externally-heated by an electric furnace (LTF 12/38/250, Lenton Ltd), with the temperature of the bed measured by a K-type thermocouple (1.5 mm dia.) inserted into the top. The flowrates of air, $\mathrm{N}_{2}, \mathrm{CO}_{2}$ and $\mathrm{CO}$ in the fluidising gas were controlled with rotameters calibrated at $293 \mathrm{~K}$ and $1 \mathrm{barg}$. A fraction of the off-gases leaving the reactor was withdrawn at $16.7 \mathrm{~mL} \mathrm{~s}^{-1}$ (STP) through a quartz probe. To prevent elutriated particles, tars and water vapour in the sampled gas entering the analysers, it was passed through (i) a glass wool filter, (ii) an impinger tube submerged in ice bath and (iii) a drying tube filled with $\mathrm{CaCl}_{2}$. The gaseous concentrations of $\mathrm{CO}_{2}$ and CO were measured with a non-dispersive, infra-red gas analyser (ABB EL3020).

In an experiment, the reactor was filled with $33 \mathrm{~g}$ of either silica sand or iron oxide particles and heated to the desired temperature, viz. $1073-1173$ K. For the gasification, the fluidising gas was typically 12.5 mol\% $\mathrm{CO}_{2}$, balance nitrogen. The total volumetric flowrate was $50 \mathrm{~mL} \mathrm{~s}^{-1}$ (STP), giving $U / U_{m f} \sim 5.2-6.0$ for sand, and $~ 2.6-3.0$ for experiments with the oxygen carrier, with $U$ being the superficial velocity at the temperature of the bed and $U_{m f}$ the value at incipient fluidisation, calculated using [15]. About $0.15 \mathrm{~g}$ of fuel were added to the reactor and allowed to gasify completely. Each experiment was repeated at least 3 times. The amount of fuel added to the bed was adjusted to ensure that the maximum conversion of $\mathrm{CO}_{2}$ to $\mathrm{CO}$ after the batch had been added was $<5 \%$, to avoid complications arising from mass transfer between the bubble and the particulate phases [14]. For experiments with iron oxide, complete conversion of $0.15 \mathrm{~g}$ of fuel to $\mathrm{CO}_{2}$ is equivalent to a conversion of $\sim 31 \%$ of the iron oxide particles from $\mathrm{Fe}_{2} \mathrm{O}_{3}$ to $\mathrm{Fe}_{3} \mathrm{O}_{4}$, i.e. reduction to $\mathrm{FeO}$, or 
$\mathrm{Fe}$, was not possible owing to an excess of hematite. The time for the batch burn-out of fuel was between 600 and $3600 \mathrm{~s}$.

A carbon balance gives the normalised rate of production of carbon monoxide, or for the experiments in $\mathrm{Fe}_{2} \mathrm{O}_{3}$, the rate of generation of $\mathrm{CO}$ by the gasification reaction, assuming carbon only enters the gas phase via Reaction (1), $R_{g}^{\prime}\left(\mathrm{mol} \mathrm{s}^{-1} \mathrm{~g}^{-1}\right)$ :

$$
R_{g}^{\prime}=2 \times\left[\frac{\dot{n}_{\text {out }}\left(y_{\mathrm{CO}, \text { out }}+y_{\mathrm{CO}_{2}, \text { out }}\right)-\dot{n}_{\text {in }}\left(y_{\mathrm{CO}, \text { in }}+y_{\mathrm{CO}_{2}, \text { in }}\right)}{m_{\text {batch }}}\right]
$$

where $m_{\text {batch }}$ is the initial mass of char added: $\dot{n}_{\text {out }}$ and $\dot{n}_{\text {in }}$ are the total molar flows leaving and entering the reactor, respectively, with $\dot{n}_{\text {out }}=\dot{n}_{\text {in }}\left(1-y_{\mathrm{CO}, \text { in }}-y_{\mathrm{CO}_{2}, \text { in }}\right)+\dot{n}_{\text {out }}\left(y_{\mathrm{CO}, \text { out }}+y_{\mathrm{CO}_{2}, \text { out }}\right)$.

\section{Theory}

\subsection{Intrinsic Kinetics of Gasification with $\mathrm{CO}_{2}$}

The generally-accepted mechanism [16] for Reaction (1) involves the adsorption of $\mathrm{CO}_{2}$ on an active site on the char, $\mathrm{C}^{*}$, followed by desorption of product $\mathrm{CO}$ :

$\mathrm{C}^{*}+\mathrm{CO}_{2(\mathrm{~g})} \underset{k_{-1}}{\stackrel{k_{1}}{\leftrightarrow}} \mathrm{C}(\mathrm{O})+\mathrm{CO}_{(\mathrm{g})}$

$\mathrm{C}(\mathrm{O}) \stackrel{k_{2}}{\rightarrow} \mathrm{C}^{*}+\mathrm{CO}_{(\mathrm{g})}$

Hence, the intrinsic chemical rate of formation of $\mathrm{CO}$ per unit mass of carbon is:

$$
R_{g, 0}^{\prime}=\frac{2 c k_{2}\left(p_{\mathrm{CO}_{2}, s}-\frac{p_{\mathrm{CO}, s}^{2}}{K_{p}}\right)}{p_{\mathrm{CO}_{2}, s}+\left(k_{2} / k_{1}\right)+\left(k_{-1} / k_{1}\right) p_{\mathrm{CO}, s}},
$$

where $p_{\mathrm{CO}, s}^{2} / K_{p}$ gives the correct behaviour close to equilibrium in Reaction (6) [5]. The rate constants $k_{1}, k_{-1}$ and $k_{2}$, are per active site, $c$ is the concentration of active sites per unit mass of sample, $K_{p}$ is the equilibrium constant for Reaction (1) and $p_{i, s}$ is the partial pressure of species $i$ at the surface of the particle. It was proposed [16] that $k_{-1} / k_{1}$ is best given by:

$k_{-1} / k_{1}=2.4 \times 10^{-4} \exp \left[-E_{k_{-1} / k_{1}} / R T\right]$ 
where $E_{k_{-1} / k_{1}}=-95 \mathrm{~kJ} \mathrm{~mol}^{-1}$, varying somewhat with the carbon [10]. The activation energy of $k_{2}$ is roughly independent of the carbon [16], with the primary difference in reactivity among carbons arising from variation in $c$, rather than from differences in the intrinsic kinetic constants. Kinetic parameters, determined by Saucedo et al. [14] are given in Table 3.

[Table 3 hereabouts]

Saucedo et al. [14] deduced that the rate of reaction at an average conversion, $X$, was

$R_{g}^{\prime}(X)=R_{g, 0}^{\prime} \times f(X)$,

where $f(X)$ is a function representing the relative change, with $X$, in the surface area available for reaction. Its form can be obtained by plotting against $X$, values of $R_{g}^{\prime}(X) / R_{g, 0}^{\prime}$ obtained from the gasification of a batch of char in a differential reactor at conditions at which the rates are controlled by intrinsic kinetics. This avoids constructing a model of the evolution of the porous structure, the assumption being that $f(X)$ is independent of the rate at which the carbon reacts. Thus, using Eqs. (7) and (9), the reaction rate of carbon per gross volume of carbon, $r_{g}\left(\mathrm{~mol} \mathrm{~m}^{-3} \mathrm{~s}^{-1}\right)$ is:

$r_{g}=\frac{R_{g, 0}^{\prime}}{2} \rho_{e} \times f(X)=\frac{c k_{1} p_{\mathrm{CO}_{2}, s}}{1+\left(k_{1} / k_{2}\right) p_{\mathrm{CO}_{2}, s}+\left(k_{-1} / k_{2}\right) p_{\mathrm{CO}, s}} \rho_{e} \times f(X)$

where $\rho_{e}$ is the initial density of the particle of char before it has reacted and $K p$ in Eq. (7) has been ignored:

$K_{p}$ is usually large, e.g. 35.8 at $1173 \mathrm{~K}$, so that, typically [14], $p_{\mathrm{CO}, s}^{2} / K_{p}<<p_{\mathrm{CO}_{2}, s}$.

\subsection{Intraparticle Mass Transfer}

Roberts and Satterfield [17] obtained effectiveness factors for rates of reactions written in the form:

$r_{g}=\frac{k p_{\mathrm{CO}_{2}, \mathrm{~s}}}{\left(1+K_{\mathrm{CO}} p_{\mathrm{CO}, \mathrm{s}}+K_{\mathrm{CO}_{2}} p_{\mathrm{CO}_{2}, \mathrm{~s}}\right)}$

where $K_{i}$ is an adsorption constant for the $i$-th species. Comparing Eqs. (10) and (11):

$k \equiv c k_{1} \rho_{e} \times f(X)$

$K_{\mathrm{CO}_{2}} \equiv k_{1} / k_{2}$ 
$K_{\mathrm{CO}} \equiv k_{-1} / k_{2}$

so that the results of [17] can be applied to the rate of intrinsic reaction defined at a particular value of $X$ in Eq. (10). Clearly, if there is a gradient in gaseous concentrations, brought about by a resistance to intraparticle mass transfer, then $X$ will vary with distance from the centre of a gasifying particle. To make the overall model amenable to an analytical solution, it has been assumed that $X$ does not vary significantly across a particle [14]. Roberts and Satterfield [17] defined parameters $K$ and $\omega$ :

$$
\begin{gathered}
K=\frac{K_{\mathrm{CO}_{2}}-\frac{D_{\mathrm{CO}_{2}}^{e f f}}{D_{\mathrm{CO}}^{e f f}} K_{\mathrm{CO}} v_{\mathrm{CO}}}{\omega} \\
\omega=1+\left(\frac{D_{\mathrm{CO}_{2}}^{e f f}}{D_{\mathrm{CO}}^{e f f}}\right) p_{\mathrm{CO}_{2}, \mathrm{~s}} K_{\mathrm{CO}} v_{\mathrm{CO}}+K_{\mathrm{CO}} p_{\mathrm{CO}, \mathrm{s}} .
\end{gathered}
$$

Here $D_{i}^{\text {eff }}$ is the effective diffusivity of the $i$-th species and $v_{\mathrm{CO}}=2$ the stoichiometric value of CO in the gasification reaction. A negative $K$ indicates inhibition by reaction products. A modified Thiele modulus, $\phi_{M}$, can also be identified [17]:

$\phi_{M}=L\left[\frac{k^{\prime} R T}{D_{\mathrm{CO}_{2}}^{e f f}}\right]^{0.5}$,

where $k^{\prime}=k / \omega$, and the characteristic dimension, $L=R_{p} / 3$, being the ratio of particle overall volume to its nominal surface area with $R_{p}$ the radius of the particle of char. In Eq. (17), $D_{\mathrm{CO}_{2}}^{e f f}=D_{\mathrm{CO}_{2}}\left(\varepsilon_{0}+\left(1-\varepsilon_{0}\right) X\right) / \tau_{\text {in }}^{2}$, where $\varepsilon_{0}$ is the initial porosity of the particle and $\tau_{\text {in }}^{2}$ is the tortuosity factor of the particle. Sundaram [18] derived expressions fitting the numerical results of [17] by

$\eta_{\text {in }}=\tanh \left(\lambda \phi^{*}\right) / \phi^{*}$

where $\phi^{*}=\phi_{M} / \phi_{c}, \phi_{c}=\sqrt{2}(1+\alpha)\left[\frac{1}{\alpha^{2}}(\alpha-\ln (1+\alpha))\right]^{0.5}, \alpha=K p_{\mathrm{CO}_{2}, s}$ and

$\lambda=1-0.4457 \alpha^{2} \phi^{*} \exp \left[-0.1153 \phi^{*^{2}}\right]$.

Hence, $\phi_{M}$ and $\alpha=K p_{\mathrm{CO}_{2}, s}$ can be calculated for different values of $X$, and $\eta_{\text {in }}$ estimated from Eqs. (17) to (19). The allowance for an effectiveness factor in the overall model is made in Section 3.3. 


\subsection{External Mass Transfer}

Assuming a spherical carbon particle gasified in $\mathrm{CO}_{2}$ (balance $\mathrm{N}_{2}$ ) and surrounded by oxygen carrier, and letting $1=\mathrm{CO}, 2=\mathrm{CO}_{2}$, and $3=\mathrm{N}_{2}$, the Stefan-Maxwell equations for the boundary layer are

$C_{T} \frac{d y_{1}}{d r}=\frac{J_{1} y_{2}-J_{2} y_{1}}{D_{B, 1,2}}+\frac{J_{1} y_{3}}{D_{B, 1,3}}$

$C_{T} \frac{d y_{2}}{d r}=\frac{J_{2} y_{1}-J_{1} y_{2}}{D_{B, 2,1}}+\frac{J_{2} y_{3}}{D_{B, 2,3}}$

$C_{T} \frac{d y_{3}}{d r}=-\frac{J_{1} y_{3}}{D_{B, 3,1}}-\frac{J_{2} y_{3}}{D_{B, 3,2}}=-y_{3}\left(\frac{J_{1}}{D_{B, 3,1}}+\frac{J_{2}}{D_{B, 3,2}}\right)$

with $J_{3}=0$. Here, $y_{i}$ and $J_{i}$ are the mole fraction and molar flux of species $i$, respectively, $C_{T}$ is the total concentration of the gas, and $D_{B, i, j}$ the binary diffusivity of species $i$ in $j$. The radial coordinate is $r$. The fluxes of $\mathrm{CO}$ and $\mathrm{CO}_{2}$ at the surface of a particle with initial radius, $R_{p}$, are respectively

$$
\begin{aligned}
& J_{1, s}=R_{g}^{\prime} \frac{\rho_{e} R_{p}}{3}=\frac{2 r_{g} R_{p}}{3} \\
& J_{2, s}=-\frac{J_{1, s}}{2}=-R^{\prime}{ }_{g} \frac{\rho_{e} R_{p}}{6}=-\frac{r_{g} R_{p}}{3},
\end{aligned}
$$

using, also, Eq. (10). Saucedo et al. [14] solved the model using the full set of equations, i.e. Eqs. (20) to (24), herein referred to as "full numerical model". Here, we seek an approximation for an analytical solution for a pseudo-binary system. Assuming that the system is dilute in CO, i.e. $y_{1} \ll y_{2}, y_{3}$, and letting all diffusivities in Eqs. (20) to (22), $D_{B, i, j}$, be equal to a constant mean diffusivity, $D_{m}$, Eq. (20) becomes:

$D_{m} C_{T} \frac{d y_{1}}{d r}=J_{1}$

For a spherical shell with radius $r$, where $r \geq R_{p}$, the material balance of $\mathrm{CO}$ around a gasifying particle surrounded by oxygen carrier, assuming isobaric conditions [14], can be described by:

$$
\left(D_{m} \varepsilon_{m f}\right) \frac{1}{r^{2}} \frac{d}{d r}\left(r^{2} \frac{d C_{1}}{d r}\right)=\frac{D_{e q}}{r^{2}} \frac{d}{d r}\left(2 r \frac{d p_{1}}{d r}+r^{2} \frac{d^{2} p_{1}}{d r^{2}}\right)=k_{l} C_{1}
$$

where $\varepsilon_{m f}$ is the mean voidage in the particulate phase of a fluidised bed, typically $\sim 0.42, D_{e q}=D_{m} \varepsilon_{m f}, C_{1}$ is the concentration of $\mathrm{CO}$ equal to $p_{1} / R T$, and $k_{l}$ is rate constant, based on volume of particulate phase, for the 
oxidation of CO by the carrier' assuming first order in $C_{1}$ ([14],[19]). Of course, if there is no carrier present $k_{l}=0$. Eq. (26) with boundary conditions:

$$
\begin{array}{ll}
r \rightarrow \infty & p_{1} \rightarrow 0 \\
r=R_{p} & p_{1} \rightarrow p_{1, s}
\end{array}
$$

yields the partial pressure of $\mathrm{CO}, p_{1}$, as a function of the radius, $r$, and $p_{1, s}$

$p_{1}=\frac{p_{1, s}}{r} \exp \left[m\left(R_{p}-r\right)\right]$

where $m^{2}=k_{l} / D_{e q}$.

From Eqs. (22) and (25) and integrating with the boundary condition

$r \rightarrow \infty \quad p_{2} \rightarrow p_{2, \text { bulk }}$

where $p_{2, \text { bulk }}$ is the partial pressure of $\mathrm{CO}_{2}$ in the bulk phase (i.e. a long way from the particle), the partial pressure of $\mathrm{CO}_{2}$ at any radius is

$$
p_{2}=p_{2, b u l k}-p_{1, s} \frac{R_{p}}{r} \exp \left[m\left(R_{p}-r\right)\right]+\frac{R_{p}^{3} R_{g}^{\prime} \rho_{e} R T}{6 D_{e q} r} .
$$

Evaluating $J_{1, s}=-\left.\frac{D_{e q}}{R T} \frac{d p_{1}}{d r}\right|_{s}$ from Eq. (29) and using Eq. (23), Eq. (31) yields

$$
p_{2, s}=p_{2, b u l k}+\frac{p_{1, s}}{2}\left(m R_{p}-1\right) .
$$

From Eq. (24),

$$
J_{2, s}=-\left.\frac{D_{e q}}{R T} \frac{d p_{2}}{d r}\right|_{s}=-r_{g} \frac{R_{p}}{3}
$$

so evaluating $\left.\frac{d p_{2}}{d r}\right|_{s}$ at the surface of the particle using Eq. (32), Eq. (33) yields:

$$
J_{2, s}=-\frac{D_{e q} p_{1, s}}{2 R T R_{p}}\left(1+m R_{p}\right)=-r_{g} \frac{R_{p}}{3}
$$

Now, substituting $r_{g}$ from Eq. (10) in Eq. (34) and rearranging gives 


$$
\begin{aligned}
& p_{1, s}^{2}\left\{\frac{3 D_{e q}\left(1+m R_{p}\right)}{2 R T R_{p}^{2} \rho_{e} c k_{2} \eta_{i n} f(X)}\left[\frac{\left(m R_{p}-1\right)}{2}+\frac{k_{-1}}{k_{1}}\right]\right\} \\
& \quad+p_{1, s}\left\{\frac{3 D_{e q}\left(1+m R_{p}\right)}{2 R T R_{p}^{2} \rho_{e} c k_{2} \eta_{i n} f(X)}\left[p_{2, \text { bulk }}+\frac{k_{2}}{k_{1}}\right]-\frac{\left(m R_{p}-1\right)}{2}\right\}-p_{2, \text { bulk }}=0,
\end{aligned}
$$

a quadratic equation in $p_{1, s}$. In Eq. (35) the effectiveness factor, $\eta_{i n}$, has been included to account for intraparticle mass transfer. In turn, $p_{2, s}$ can be calculated from Eq. (32). To solve the overall model at a particular value of $X$, an initial estimate of $p_{1, s}$ and $p_{2, s}$ was made using Eq. (35), assuming $\eta_{\text {in }}=1$. Then, the calculated partial pressures at the surface of the particle were used to calculate $\eta_{\text {in }}$ from Eqs. (12) to (19). A new estimate of $p_{1, s}$ and $p_{2, s}$ was calculated as before and used to recalculate $\eta_{i n}$, iteratively, thus the overall rate of gasification was estimated.

The model proposed in [14] used a full solution of the Stefan-Maxwell equations for non-equimolar counter diffusion (non-EMCD) inside and outside the char, and showed excellent agreement with the reaction rates observed experimentally between 1073 and $1173 \mathrm{~K}$. Thus, the following results and discussion compare the results predicted using the pseudo-binary model proposed here and those from the model in [14] with the experiments.

\section{Results}

Figure 1 shows concentration profiles around a char particle being gasified in $12.5 \mathrm{~mol} \% \mathrm{CO}_{2}$, balance $\mathrm{N}_{2}$, with, and without, an oxygen carrier using the pseudo-binary model. At $1173 \mathrm{~K}$ and in an inert bed, CO accumulates at the surface $\left(y_{\mathrm{CO}, s} \sim 0.025\right)$, inhibiting gasification and suggesting external mass transfer limitations. When $\mathrm{Fe}_{2} \mathrm{O}_{3}$ is present, the model predicts that most of the $\mathrm{CO}$ is immediately oxidised to $\mathrm{CO}_{2}$ ( $y_{\mathrm{CO}, s} \sim 0.007$ ), thus increasing the $\left[\mathrm{CO}_{2}\right]$ at the surface of the particle. Furthermore, the predicted overall reaction rate is $\sim 21 \%$ higher in a bed of $\mathrm{Fe}_{2} \mathrm{O}_{3}$ than in a bed of sand. The results are in good agreement with the full numerical model [14], where external mass transfer was significant at $T>1123 \mathrm{~K}$.

\section{[Figure 1 hereabouts]}

Figure 2 compares the predicted rates of gasification at $1073 \mathrm{~K}$ for different conversions, $X$, using both the pseudo-binary and the full numerical models and shows excellent agreement between them for both 
sand and $\mathrm{Fe}_{2} \mathrm{O}_{3}$. However, at this temperature, the rate was largely kinetically controlled [14], with $\eta_{\text {in }}>0.90$ and with negligible accumulation of $\mathrm{CO}$ at the surface of the particle. Thus, the effect of $\mathrm{Fe}_{2} \mathrm{O}_{3}$, which only affects the concentrations when $\sigma_{r}>1$ (where $\sigma_{r}=r / R_{p}$ ), is very small. Although not shown, excellent agreement between the predicted rates using the two models was also observed at $1123 \mathrm{~K}$.

\section{[Figure 2 hereabouts]}

Any error in pseudo-binary diffusion of species in the analytical model should be more noticeable at higher temperatures at which the gasification rate is faster and where external mass transfer becomes significant, i.e. $T \geq 1123 \mathrm{~K}$ [14], leading to relatively high concentrations of $\mathrm{CO}$ at the surface of the particle. Figure 3 compares the predicted rates at different conversions at $1173 \mathrm{~K}$. At $X=0$, the effect of $\mathrm{Fe}_{2} \mathrm{O}_{3}$ on the overall rate is relatively small since the predicted $[\mathrm{CO}]$ at the surface of the particle is relatively low $(\sim 0.014)$ and the reaction is mainly limited by intraparticle diffusion $\left(\eta_{i n} \sim 0.77\right.$ [14]). As the reaction proceeds and conversion increases, an increase in porosity is expected, accounted for in the pseudo-binary solution by the effective diffusivity in Eq. (17). Furthermore, there is also an increase in the overall activity of gasification as the surface area increases from $X=0$ to $X=0.2$, reflected in $f(X)$ (derived in [14] and used in this work). In general, this increase in rate leads to the accumulation of more $\mathrm{CO}$ at the surface of the particle. Hence, in the presence of $\mathrm{Fe}_{2} \mathrm{O}_{3}$, the rate of reaction would be much faster than that in sand. Additionally, at $X=0.2$, the increase in porosity increased the internal effectiveness, i.e. the particle is less limited by internal mass transfer than at $X=0$. The increase in the effective diffusivity of gases within the particle and the overall activity of the particle due to the increase in the surface area available for reaction means that there is a large difference between the amount of $\mathrm{CO}$ accumulated at the surface of the particle, depending on whether it was gasified in sand or $\mathrm{Fe}_{2} \mathrm{O}_{3}$. Thus, the effect of $\mathrm{Fe}_{2} \mathrm{O}_{3}$ is more significant under these conditions owing to the oxidation of $\mathrm{CO}$ by the oxygen carrier to $\mathrm{CO}_{2}$. In the later stages of the reaction, e.g. at $X=0.5$ and 0.7 , the surface area decreases owing to the overlapping of pores (also accounted for by $f(X)$ ) and the overall activity decreases. Finally, larger differences in the predicted rates were found between the models at $1173 \mathrm{~K}$. At $X=0$ and in a bed of $\mathrm{Fe}_{2} \mathrm{O}_{3}$, the pseudo-binary solution predicted an overall rate of reaction $\sim 16 \%$ higher than 
the full numerical model: for $X \geq 0.2$, the average absolute error was $\sim 8 \pm 1 \%$. For sand the absolute error for all four conversions was $\sim 13 \pm 2 \%$.

[Figure 3 hereabouts]

\section{Discussion}

At 1073 and $1123 \mathrm{~K}$, the values of $\eta_{i n}$ used with the pseudo-binary model are very similar to those estimated using the full numerical model at all conversions: the absolute deviations are within $2 \%$. However, at $1173 \mathrm{~K}$, the difference in the predicted $\eta_{i n}$ is more significant: the pseudo-binary solution, which used Roberts and Satterfield's [17] work, estimates values of $\eta_{i n} \sim 12 \%, 7 \%, 5 \%$ and $3 \%$ higher than the full numerical model at $X=0,0.2,0.5$ and 0.7 , respectively. Thus, to investigate whether the main discrepancy between the two models at $1173 \mathrm{~K}$ was caused by deviations within or external to the particle, the results originally shown in Fig. 3 were re-calculated using the values of $\eta_{\text {in }}$ from the full numerical model [14] in the pseudo-binary solution, i.e. isolating the effect of assuming pseudo-binary diffusion in the external boundary layer. Results are shown in Fig. 4. The new predicted values with the pseudo-binary solution agree with the full numerical model to within $\sim 3 \pm 2 \%$ for $\mathrm{Fe}_{2} \mathrm{O}_{3}$ and all four conversions. For sand, the deviation at $X=0$ was below $1 \%$ and $\sim 8 \pm 3 \%$ for $X \geq 0.2$. These deviations are significantly lower than those seen in Fig. 3, indicating that a significant share of the error of the predicted rates with the pseudo-binary solution is caused by underestimating intraparticle diffusional resistance rather than by assuming pseudo-binary diffusion external to the particle.

\section{[Figure 4 hereabouts]}

The pseudo-binary model was used to estimate the enhancement of the overall rate of reaction when gasifying lignite char in a bed of $\mathrm{Fe}_{2} \mathrm{O}_{3}$, arising from the oxidation of $\mathrm{CO}$ to $\mathrm{CO}_{2}$ in the boundary layer by the carrier, i.e. reducing external mass transfer effects. Defining the relative rate of reaction as the rate when $\mathrm{Fe}_{2} \mathrm{O}_{3}$ is present divided by the rate in its absence, the enhancement effect was studied as a function of the "reaction modulus", $m R_{p}$, arising in the equations to determine the external mass transfer in Section 3.3. If $R_{p}$ 
is constant, varying the $m R_{p}$ effectively means investigating variations in $k_{l}$, assuming $D_{e q}$ is fixed. Figure 5 shows resulting plots. At $1073 \mathrm{~K}$, little external mass transfer limitation exists so that the relative rate at different reaction moduli is almost constant at $\sim 1.03$ at $X=0$ and $\sim 1.06$ at $X=0.2$. However, at $1173 \mathrm{~K}$, the relative rate increases continuously as $m R_{p}$ increases, particularly at $X=0.2$ (e.g. the relative rate for $m R_{p}=0.5$ is $\sim 1.09$ and as high as $\sim 1.25$ for $m R_{p}=5.0$ ). This indicates that significant enhancement of the overall rate of gasification occurs with a reactive lignite char at high temperatures and in the presence of an oxygen carrier capable of oxidising rapidly the products of gasification.

\section{[Figure 5 hereabouts]}

\section{Conclusions}

Batch gasification experiments with lignite char show an enhancement of the apparent rate of gasification of char when $\mathrm{Fe}_{2} \mathrm{O}_{3}$ is present in the fluidised bed, especially above $1123 \mathrm{~K}$. Such conditions corresponded to the point at which mass transfer limitations within and surrounding the particle became significant, and suggested that the $\mathrm{Fe}_{2} \mathrm{O}_{3}$ was influencing external mass transfer and hence the rate of gasification. Furthermore, at conversions of $X \approx 0.2$, the surface area available for reaction is at its maximum, giving a significant increase in observed rate. A particle of char at $X=0.2$ experiences less mass transfer resistance within the particle compared to its initial conditions. When this factor is coupled with the increased surface area, there results a larger build-up of $\mathrm{CO}$ at the surface of the particle than is present at the start of the reaction. Hence, the ability of $\mathrm{Fe}_{2} \mathrm{O}_{3}$ to remove $\mathrm{CO}$ from the surface of the particle leads to a significant difference between rates of gasification in sand and $\mathrm{Fe}_{2} \mathrm{O}_{3}$, particularly when $X \approx 0.2$. Thus, when external mass transfer begins to affect the rate, conversion of $\mathrm{CO}$ to $\mathrm{CO}_{2}$ by the $\mathrm{Fe}_{2} \mathrm{O}_{3}$ in the boundary layer enhances the rate of removal of inhibitory $\mathrm{CO}$ from the particle, whilst regenerating the reactant $\mathrm{CO}_{2}$, effectively removing the limitation caused by external mass transfer.

The predicted rates with the pseudo-binary solution were compared with a model using a full solution of the Stefan-Maxwell equations for non-equimolar counter diffusion (non-EMCD) inside and outside the char, with excellent agreement between the rates predicted at $T \leq 1123 \mathrm{~K}$. However, for $T \geq 1173 \mathrm{~K}$, the pseudobinary solution predicted higher overall rates (up to 16\%) than the full numerical model owing, largely, to 
lower intraparticle limitations estimated with the pseudo-binary solution, rather than as a consequence of assuming a uniform diffusivity.

\section{References}

[1] J. S. Dennis, S. A. Scott, A. N. Hayhurst, J. Energy Inst. 79 (3) (2006) 187-190.

[2] S. A. Scott, J. S. Dennis, A. N. Hayhurst, T. Brown, AIChE J. 52 (9) (2006) 3325-3328.

[3] H. Leion, T. Mattisson, A. Lyngfelt, Fuel 86 (12-13) (2007) 1947-1958.

[4] T. A. Brown, J. S. Dennis, S. A. Scott, J. F. Davidson, A. N. Hayhurst, Energy Fuels 24 (5) (2010) 3034-3048.

[5] J. S. Dennis, S. A. Scott, Fuel 89 (7) (2010) 1623-1640.

[6] R. K. Lyon, J. A. Cole, Combust. Flame 121 (1-2) (2000) 249-261.

[7] H. Leion, T. Mattisson, A. Lyngfelt, Int. J. Greenh. Gas Control 2 (2) (2008) 180-193.

[8] C. Linderholm, A. Lyngfelt, A. Cuadrat, E. Jerndal, Fuel 102 (2012) 808-822.

[9] A. Cuadrat, A. Abad, F. García-Labiano, P. Gayán, L. F. de Diego, J. Adánez, Chem. Eng. J. 195-196 (2012) 91-102.

[10] N. M. Laurendeau, Prog. Energy Combust. Sci. 4 (4) (1978) 221-270,

[11] M. Mentser, S. Ergun, Carbon 5 (4) (1967) 331-337.

[12] R. H. Essenhigh, Fundamentals of Coal Combustion, Wiley, 1981, p. 160.

[13] B. J. McBride, M. J. Zehe, S. Gordon, NASA Glenn Coefficients for Calculating Thermodynamic Properties of Individual Species, technical report: NASA, 2002.

[14] M. A. Saucedo, J. Y. Lim, J. S. Dennis, S. A. Scott, Fuel 127 (2014) 186-201.

[15] C. Y. Wen, Y. H. Yu, AIChE J. 12 (3) (1966) 610-612.

[16] S. Ergun, J. Phys. Chem. 60 (4) (1956) 480-485.

[17] G. W. Roberts, C. N. Satterfield, Ind. Eng. Chem. Fundam. 4 (3) (1965) 288-293.

[18] K. Meenakshi-Sundaram, Chem. Eng. Commun. 15 (5-6) (1982) 305-311.

[19] C. D. Bohn, J. P. Cleeton, C. R. Müller, J. F. Davidson, A. N. Hayhurst, S. A. Scott, J. S. Dennis, AIChE J. 56 (4) (2010) 1016-1029. 
Table 1

Table 1.

Thermodynamic information [13]

\begin{tabular}{lccl}
\hline Reaction & $\Delta H_{1173 K}^{0}$ & $\Delta G_{1173 K}^{0}$ & \\
\hline $\begin{array}{c}3 \mathrm{Fe}_{2} \mathrm{O}_{3(\mathrm{~s})}+\mathrm{CO}_{(\mathrm{g})} \rightarrow \\
2 \mathrm{Fe}_{3} \mathrm{O}_{4(\mathrm{~s})}+\mathrm{CO}_{2(\mathrm{~g})}\end{array}$ & -38.6 & -108.2 & $(2)$ \\
$\begin{array}{c}0.947 \mathrm{Fe}_{3} \mathrm{O}_{4(\mathrm{~s})}+0.788 \mathrm{CO}_{(\mathrm{g})} \rightarrow \\
3 \mathrm{Fe}_{0.947} \mathrm{O}_{(\mathrm{s})}+0.788 \mathrm{CO}_{2(\mathrm{~g})}\end{array}$ & +16.7 & -5.5 & \\
\hline
\end{tabular}


Table 2.

Proximate and ultimate analyses.

\begin{tabular}{l|c|c|c} 
ar = as received & \multicolumn{2}{|c|}{ Lignite coal } & Lignite \\
wd = mass dry & ar & wd & char \\
\hline
\end{tabular}

Proximate analysis (wt.\%)

\begin{tabular}{l|r|r|r}
\hline Moisture & 54.1 & - & ND \\
Ash content & 2.12 & 5.52 & 8.76 \\
Volatile matter & 22.2 & 50.7 & ND \\
Fixed carbon & 19.9 & 45.6 & ND \\
\hline \multicolumn{3}{|l}{ Ultimate analysis (wt. \%) } \\
\hline C & 30.6 & 69.8 & 85.69 \\
H & 8.5 & 5.47 & 0.82 \\
S & 0.14 & 0.31 & 0.6 \\
$\mathrm{~N}$ & 0.41 & 0.93 & 0.84 \\
O (balance) & 58.23 & 17.97 & 3.3 \\
\hline
\end{tabular}


Table 3.

Values of parameters for the temperature dependence of the intrinsic parameters for the gasification of char with $\mathrm{CO}_{2}$.

\begin{tabular}{c|c|c|c|c|c}
\hline $\begin{array}{c}A_{2 c k_{2}} / \\
\mathrm{mol} \mathrm{s}^{-1} \mathrm{~g}^{-1}\end{array}$ & $\begin{array}{c}E_{2 c k_{2}} / \\
\mathrm{kJ} \mathrm{mol}^{-1}\end{array}$ & $\begin{array}{c}A_{2 c k_{1}} / \\
\mathrm{mol} \mathrm{s}^{-1} \mathrm{~g}^{-1} \mathrm{bar}^{-1}\end{array}$ & $\begin{array}{c}E_{2 c k_{1}} / \\
\mathrm{kJ} \mathrm{mol}^{-1}\end{array}$ & $\begin{array}{c}A_{k_{-1} / k_{1}} / \\
-\end{array}$ & $\begin{array}{c}E_{k_{-1} / k_{1}} / \\
\mathrm{kJ} \mathrm{mol}^{-1}\end{array}$ \\
\hline $1.26 \pm 0.1 \times 10^{11}$ & $290 \pm 20$ & $2.56 \pm 0.2 \times 10^{6}$ & $200 \pm 20$ & $2.4 \pm 0.2 \times 10^{-4}$ & $-91 \pm 2$ \\
\hline
\end{tabular}




\section{List of Figure Captions}

Figure 1. Predicted mole fraction profile of $\mathrm{CO}$ and $\mathrm{CO}_{2}$ as a function of the dimensionless radius, $\sigma_{r}=r / R_{p}$, for a char particle, $d_{p}=800 \mu \mathrm{m}$, gasified in $12.5 \mathrm{~mol} \% \mathrm{CO}_{2}$, balance $\mathrm{N}_{2}$, in a bed of either $\mathrm{Fe}_{2} \mathrm{O}_{3}$ or sand, at $1173 \mathrm{~K}$ and $X=0.2$. Results using the pseudo-binary solution described in Section 3 .

Figure 2. Comparison between the experimentally-observed rates and the predicted rates using the full numerical model and the pseudo-binary solution for both internal and external mass transfer at $1073 \mathrm{~K}$.

Figure 3. Comparison between the experimentally-observed rates and the predicted rates using the full numerical model and the pseudo-binary solution for both internal and external mass transfer at $1173 \mathrm{~K}$.

Figure 4. Comparison between the experimentally-observed rates and the predicted rates using the full numerical model and the pseudo-binary solution at $1173 \mathrm{~K}$. For the pseudo-binary solution, the effectiveness factors, $\eta_{i n}$, used here were the same as those estimated in [14]. N.B. At $X=0.2$ and with iron oxide, the predicted results with the two models overlap.

Figure 5. Relative rate, $R_{g}^{\prime}\left(m R_{p}\right) / R_{g}^{\prime}\left(m R_{p}=0\right)$, as a function of the reaction modulus, $m R_{p}$, at 1073 and $1173 \mathrm{~K}$ and at $X=0.0$ and 0.2 . Results calculated using the pseudo-binary solution keeping $R_{p}$ constant $(0.4 \mathrm{~mm})$. N.B. The originally-calculated reaction moduli were $\sim 2.6$ and $\sim 3.4$ at 1073 and $1173 \mathrm{~K}$, respectively. 
Figure 1

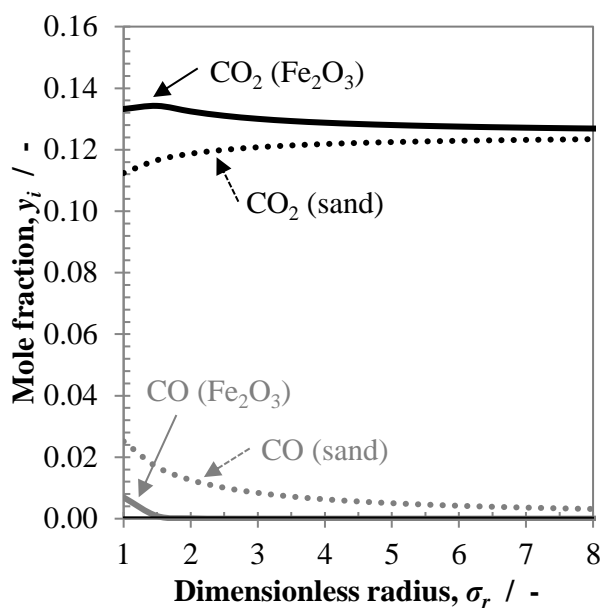

Figure 1. 
Figure 2

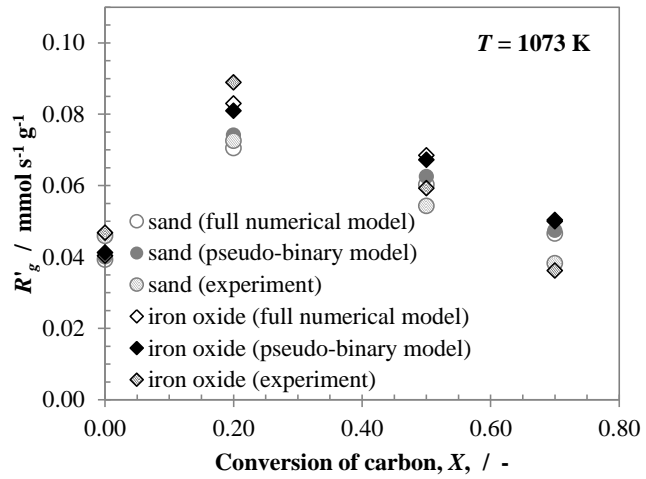

Figure 2. 
Figure 3

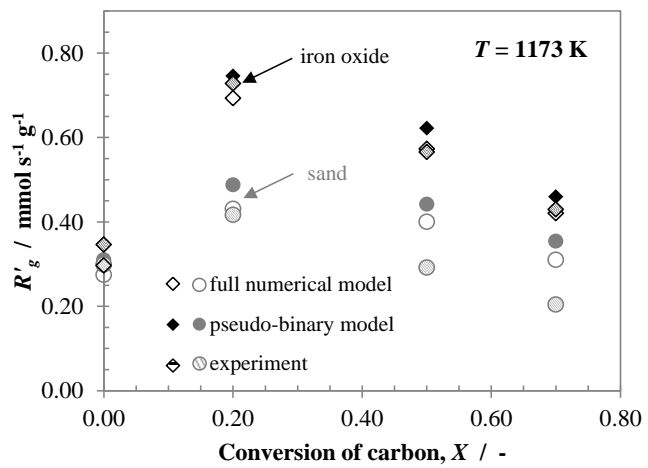

Figure 3. 
Figure 4

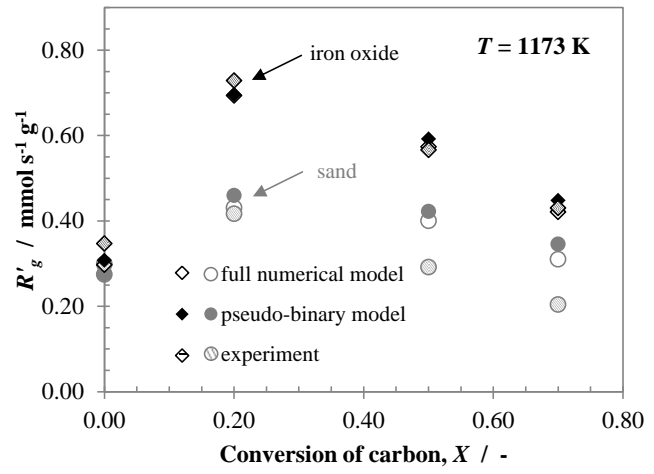

Figure 4. 
Figure 5

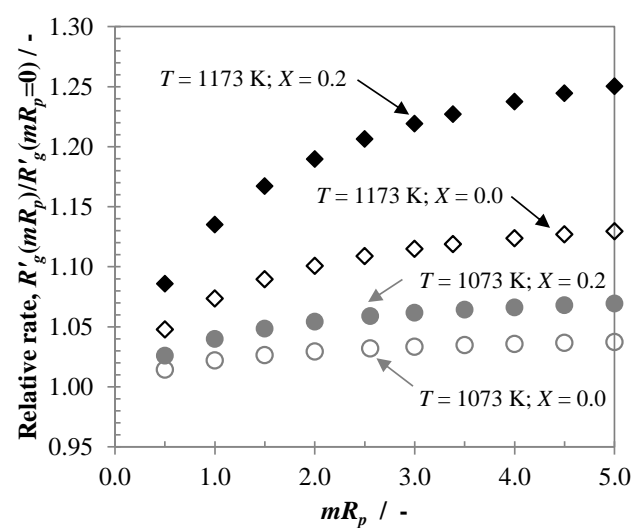

Figure 5. 